\title{
Risk Factors for Surgical Site Infection after Hip Arthroplasty: A Multicentric Study
}

\author{
Gabriel B. Tofani ${ }^{1}$, Gustavo P. Irffi ${ }^{1}$, Lucas F. Silva ${ }^{2}$, Cynthia C. M. da Silva ${ }^{2}$, \\ Bráulio R. G. M. Couto², Gilberto D. Miranda ${ }^{3}$, Carlos E. F. Starling ${ }^{4}$ \\ ${ }^{1}$ Institute of Biological Sciences, Centro Universitário de Belo Horizonte-UniBH, Belo Horizonte, Brazil \\ ${ }^{2}$ Institute of Engineering and Technology, Centro Universitário de Belo Horizonte-UniBH, Belo Horizonte, \\ Brazil \\ ${ }^{3}$ Faculdade de Ciências Médicas e da Saúde de Juiz de Fora-SUPREMA, Juiz de Fora, Brazil \\ ${ }^{4}$ Hospitals Life Center, Vera Cruz, and Baleia, Belo Horizonte, Brazil \\ Email: coutobraulio@hotmail.com
}

Received 30 December 2015; accepted 11 February 2016; published 14 February 2016

Copyright (C) 2016 by authors and Scientific Research Publishing Inc.

This work is licensed under the Creative Commons Attribution International License (CC BY).

http://creativecommons.org/licenses/by/4.0/

(c) (i) Open Access

\section{Abstract}

The objective of this study is to answer three main questions: What is the risk of wound infection for patients undergoing hip arthroplasty? What are the main etiologicagents of surgical site infection (SSI)? What are the risk factors most associated with surgical site infection? Method: This was a multicentric, retrospective cohort study which analyzed data collected in five general hospitals in Belo Horizonte, Brazil, between the period of January 2009 and December 2013. The continuous parameters studied were age, length of hospital stay before surgery, duration of surgery, number of professionals at surgery and number of hospital admissions. Categorical variables were surgical wound classification (clean, clean contaminated, contaminated, dirty/infected), American Society of Anesthesiologists (ASA) score (I, II, III, IV, V), type of surgery (elective, emergency), general anesthesia (yes, no), prophylactic antibiotic (yes, no), trauma surgery (yes, no) and Nosocomial Infections Surveillance (NNIS) risk index (IRIC = 0, 1, 2, 3). Results: Estimated SSI risk was $3.2 \%(95 \%$ C.I. $=2.6 \%$ to $4.1 \%)$ and risk of osteomyelitis was $0.6 \%(95 \%$ C.I. $=0.4 \%$ to $1.1 \%)$. ASA score $>2$, general anesthesia, length of hospital stay before surgery higher than four days, more than two professionals at surgical field and duration of surgery higher than five hours were risk factors for SSI after hip prosthesis $(p<0.05)$. The final multiple logistic regression analysis indicated that the modified NNIS risk was independently associated with surgical site infection after arthroplasty of hip. Conclusion: Despite the modified NNIS index being a risk factor for SSI, none of its independent variables was statistically significantly in the logistic model $(p>0.100)$. Each modified NNIS risk category increased the chance of a patient being infected by almost three times, when compared with the previous category $(\mathrm{OR}=2.82 ; p=0.011)$. 


\section{Keywords}

\section{Surgical Site Infection, Hip Arthroplasty, Hip Replacement, Risk Factors}

\section{Introduction}

Total hip arthroplasty (THA) is one of the most common orthopedic interventions [1] and is indicated for patients who fail to respond to clinical treatment such as pharmacotherapy with analgesics or anti-inflammatories, physical therapy or exercise [2]. It involves the replacement of a damaged hip joint with an artificial prosthesis [2] and is effective in treating not only pain but also the disability following hip joint degenerative diseases [1]-[4]. However, surgical site infection (SSI) is a significant cause of patient morbidity and mortality [5] and its risk factors must be assessed prior to surgery.

There are several types of hip arthroplasty, and the choice of which one to use is dependent on patients' needs and on the experience of the professionals. It is not the objective of this paper to explore the different procedures involved in THA. A meta-analysis published in 2014 showed that most evidence indicated no difference for post-surgery scores for functional and clinical measures between the different types of THA, even though the study was impaired due to missing data and poor reporting [2].

The number of THAs is steadily increasing and it is projected that by 2020, it will exceed 500,000 procedures per year [4]. The rate of SSI following THA has been estimated to range between $0.2 \%$ and $1.1 \%$ depending on the time after surgery [4] and the incidence of prosthetic joint infection lies between $0.4 \%$ to $1 \%$ [6]. The increasing number of THAs performed means an increase in the absolute number of patients presenting with these complications. Infection is the third most common cause of revision THA [3] and it has a substantial economic impact on the healthcare system as it increases the length of hospital stay and escalates hospital costs [3] [5]. Hence, prevention of infection is imperative.

Some factors are known to increase the risk of infection after surgery. Patient-related factors include (but are not limited to) age, gender, obesity and American Society of Anesthesiologists (ASA) score, while surgery-related factors include duration of surgery, antibiotic prophylaxis, type of anesthesia and NNIS Index score [3]-[5]. Nonetheless, studies still yield inconsistent results regarding the role of these factors in increasing infection risk [4]. Thus, the objective of our study is to answer three questions: What is the risk of wound infection in patients undergoing hip replacement? What are the main etiologic agents in surgical site infection following hip arthroplasty? What are the risk factors most associated with SSI following this procedure?

\section{Materials and Methods}

This multicentric retrospective cohort study assessed SSI risk factors in patients undergoing total hip replacement during the period of January, 2009 to December, 2013 in five general hospitals in Belo Horizonte, Brazil.

The Hospital Infection Control Committees (HICC) of these hospitals gathered all the data used in our analysis during their routine procedures for surgical site infection surveillance following standard methods defined by the National Healthcare Safety Network (NHSN). The outcome variables were surgical site infection and osteomyelitis. The preoperative and operative parameters were divided into continuous and categorical variables. The former includes age, duration of hospital stay before surgery, duration of surgery, number of professionals involved in surgery and number of hospital admissions. The latter were surgical wound classification, the American Society of Anesthesiologists (ASA) preoperative assessment score, type of surgery (elective, emergency), general anesthesia (yes, no), prophylactic antibiotics (yes, no), trauma surgery (yes, no) and Nosocomial Infections Surveillance-NNIS risk index $(0,1,2,3)$.

Risk and protection factors for infection were identified by bilateral statistical hypothesis testing; the significance level was $5 \%(\alpha=0.05)$.Student's t test or non-parametric tests were applied to assess continuous variables. The chi-square or Fisher's exact test were used to analyze categorical variables, when necessary.

Analysis of each factor yielded a point estimate at a 95\% confidence interval (C.I.-95\%) for relative risk. A multivariate analysis with logistic regression was applied in the last phase of the study. Variables tested in the logistic model were selected when the univariate analysis generated a $p$-value $\leq 0.25$. 


\section{Results}

A total of 2,161 patients undergoing hip arthroplasty in five Brazilian general hospitals during January, 2009 to December, 2013 were enrolled in our study. Surgical site infections were diagnosed in 70 of those patients while osteomyelitis were identified in 14 patients. The estimated SSI risk was 3.2\% (C.I. 95\% $=[2.6 \%-4.1 \%]$ ) and the risk of osteomyelitis was $0.6 \%$ [C.I. $95 \%=[0.4 \%-1.1 \%]$ ).

The etiology of SSIs was identified in $70 \%$ of the cases and 65 different microorganisms were found in 49 SSIs: 27 Staphylococcus aureus (44\%), 7 Acinetobacter baumannii (11\%), 6 Escherichia coli (10\%), 5 Pseudomonas aeruginosa (8\%), and 19 were other microorganisms. The main etiologic agent in osteomyelitis was Staphylococcus aureus-61\% of cases, followed by Escherichia coli (2), Acinetobacter baumannii (2), and Staphylococcus epidermidis (1).

The results of our univariate analysis of the continuous variables are shown in Table 1. The length of hospital stay before surgery ( $p$-value $<0.001$ ) was suggested as risk factor for SSI after THA. Table 2 shows the results of the univariate analysis of categorical variables. General anesthesia ( $p$-value $=0.029)$, number of professionals at surgery higher than 2 ( $p$-value $=0.003$ ), length of hospital stay higher than 4 days $(p$-value $=0.16$ ) and ASA score higher than 2 ( $p$-value $=0.011$ ) were also indicated as risk factors for the development of SSI. Although several values were missing, our analysis strongly suggests that prophylactic antibiotic before surgery protected patients against SSIs.

Table 3 shows the results of our multivariate analysis, in which only the modified NNIS risk was independently associated with SSI following THA. No patient in our sample had four risk factors for infection, thus, Figure 1 shows a modified risk index ranging from 0 to 3 . The SSI risk increases from $1 \%$ when the patient has no risk factors to $25 \%$ in patients with three risk factors.

The Modified NNIS risk index values range from 0 to 4 points and are defined by four independent and equally weighted variables. One point is given for each of the following factors: ASA score higher than two, wound classification as either contaminated or dirty/infected, duration of surgery over two hours (75th percentile for duration of hip replacement), and the need for general anesthesia.

\section{Discussion}

The risk of surgical site infection, as aforementioned, is estimated to be between $0.2 \%$ to $1.1 \%$ [4]. In our study, we encountered a risk that was practically three times higher.

Native microorganisms of the skin are the most associated with SSI [3]. Based on genotyping evaluations, [7] showed that the source of infection was endogenous in more than $80 \%$ of nosocomial infections with Staphylococcus aureus. This same microorganism was the most commonly identified in our study, with a prevalence of

\begin{tabular}{|c|c|c|c|c|c|}
\hline Variable & SSI & Mean & Median & $\begin{array}{l}\text { Standard } \\
\text { Deviation }\end{array}$ & $p$-value \\
\hline \multirow{2}{*}{ Age (Years) } & Yes & 62.3 & 64 & 20.5 & \multirow{2}{*}{0.29} \\
\hline & No & 65 & 67 & 16.4 & \\
\hline \multirow{2}{*}{$\begin{array}{l}\text { Length of Hospital Stay } \\
\text { Before Surgery (Days) }\end{array}$} & Yes & 3.2 & 1 & 6.8 & \multirow{2}{*}{$<0.001^{*}$} \\
\hline & No & 1.6 & 0 & 5.4 & \\
\hline \multirow{2}{*}{$\begin{array}{c}\text { Durationof Surgery } \\
\text { (Hours) }\end{array}$} & Yes & 2.7 & 2.5 & 1.2 & \multirow{2}{*}{0.158} \\
\hline & No & 2.5 & 2.3 & 1 & \\
\hline \multirow{2}{*}{$\begin{array}{c}\text { Number of Professionals } \\
\text { at Surgery }\end{array}$} & Yes & 1.8 & 1 & 1 & \multirow{2}{*}{$0.080^{*}$} \\
\hline & No & 1.9 & 2 & 0.7 & \\
\hline \multirow{2}{*}{$\begin{array}{l}\text { Numberof Hospital } \\
\text { Admissions }\end{array}$} & Yes & 1.4 & 1 & 0.8 & \multirow{2}{*}{0.216} \\
\hline & No & 1.3 & 1 & 0.7 & \\
\hline
\end{tabular}

*Mann-Whitney/Wilcoxon Two-Sample Test. Other $p$-values calculated by student T-test. 
Table 2. Univariate analysis of categorical variables.

\begin{tabular}{|c|c|c|c|c|c|c|c|}
\hline Variable & Categories & $\mathrm{n}$ & SSI & SSI Risk (\%) & $\mathrm{RR}$ & [C.I. 95\% R.R.] & $p$-value \\
\hline \multirow{2}{*}{$\begin{array}{l}\text { Surgical Wound } \\
\text { Classification }\end{array}$} & Contaminatedordirty/infected & 29 & 2.00 & $6.9 \%$ & \multirow[b]{2}{*}{2.63} & \multirow[b]{2}{*}[0.67;10.35]{} & \multirow[b]{2}{*}{0.183} \\
\hline & Clean or clean-contaminated & 1602 & 42.00 & $2.6 \%$ & & & \\
\hline \multirow{2}{*}{$\begin{array}{c}\text { American Society of } \\
\text { Anesthesiologists (ASA) }\end{array}$} & $>2$ & 321 & 16.00 & $5.0 \%$ & \multirow{2}{*}{2.29} & \multirow{2}{*}[1.25;4.18]{} & \multirow{2}{*}{0.011} \\
\hline & $\leq 2$ & 1286 & 28.00 & $2.2 \%$ & & & \\
\hline \multirow{2}{*}{ Type of Surgery } & Emergency & 83 & 4.00 & $4.8 \%$ & \multirow{2}{*}{1.96} & \multirow{2}{*}[0.71;5.36]{} & \multirow{2}{*}{0.164} \\
\hline & Elective & 1501 & 37.00 & $2.5 \%$ & & & \\
\hline \multirow[b]{2}{*}{ General Anesthesia } & Yes & 697 & 29.00 & $4.2 \%$ & \multirow[b]{2}{*}{1.88} & \multirow[b]{2}{*}[1.09;3.24]{} & \multirow[b]{2}{*}{0.029} \\
\hline & No & 993 & 22.00 & $2.2 \%$ & & & \\
\hline \multirow{2}{*}{ Prophylactic Antibiotic } & Yes & 772 & 39.00 & $5.1 \%$ & \multirow{2}{*}{0.41} & \multirow{2}{*}[0.18;0.93]{} & \multirow{2}{*}{0.045} \\
\hline & No & 49 & 6.00 & $12.2 \%$ & & & \\
\hline \multirow{2}{*}{ Trauma Surgery } & Yes & 136 & 4.00 & $2.9 \%$ & \multirow[b]{2}{*}{1.27} & \multirow[b]{2}{*}[0.46;3.52]{} & \multirow[b]{2}{*}{0.558} \\
\hline & No & 1422 & 33.00 & $2.3 \%$ & & & \\
\hline \multirow{3}{*}{ NNIS Risk Index } & 0 & 1017 & 13.00 & $1.3 \%$ & \multirow{3}{*}{-} & \multirow{3}{*}{ - } & \multirow{3}{*}{$<0.001$} \\
\hline & 1 & 329 & 15.00 & $4.6 \%$ & & & \\
\hline & 2 & 20 & 3.00 & $15.0 \%$ & & & \\
\hline \multirow{2}{*}{$\begin{array}{l}\text { Length of Hospital Stay } \\
\text { Before Surgery (Days) }\end{array}$} & $>4$ & 187 & 12.00 & $6.4 \%$ & \multirow{2}{*}{2.18} & \multirow{2}{*}{ [1.19; 3.99] } & \multirow{2}{*}{0.016} \\
\hline & $\leq 4$ & 1974 & 58.00 & $2.9 \%$ & & & \\
\hline Number of Professionals & $>2$ & 234 & 14.00 & $6.0 \%$ & & & \\
\hline & $\leq 2$ & 1822 & 40.00 & $2.2 \%$ & & & \\
\hline & Yes & 1750 & 53.00 & $3.0 \%$ & & & \\
\hline First Hospital Admission & No & 411 & 17.00 & $4.1 \%$ & 0.73 & {$[0.43 ; 1.25]$} & 0.277 \\
\hline & $>60$ & 1377 & 43.00 & $3.1 \%$ & & & \\
\hline Age (Years) & $<60$ & 784 & 27.00 & $3.4 \%$ & 0.91 & {$[0.56 ; 1.46]$} & 0.705 \\
\hline Duration of Suroery & $>2$ & 1003 & 33.00 & $3.3 \%$ & & & \\
\hline (Hours) & $\leq 2$ & 621 & 18.00 & $2.9 \%$ & 1.14 & {$[0.64 ; 2.0]$} & $0.7 / 0$ \\
\hline
\end{tabular}

Table 3. Multivariate analysis.

\begin{tabular}{|c|c|c|c|c|c|}
\hline Variable & Coefficient & Standard Error & p-value & OddsRatio & [C.I. 95\%] \\
\hline $\mathrm{ASA}>2$ & -0.54 & 0.65 & 0.408 & 0.58 & {$[0.16 ; 2.09]$} \\
\hline DurationofSurgery $>2$ hours & -0.39 & 0.42 & 0.362 & 0.68 & {$[0.30 ; 1.56]$} \\
\hline $\begin{array}{l}\text { Surgical Wound Classification: } \\
\text { Contaminated or dirty/infected }\end{array}$ & -0.17 & 0.98 & 0.866 & 0.85 & {$[0.12 ; 5.81]$} \\
\hline NNIS Risk Index & 0.55 & 0.71 & 0.444 & 1.73 & {$[0.43 ; 7.00]$} \\
\hline Modified NNIS Risk Index & 1.04 & 0.41 & 0.011 & 2.82 & {$[1.27 ; 6.26]$} \\
\hline Constant & -4.63 & 0.42 & 0 & 0.01 & 0 \\
\hline
\end{tabular}




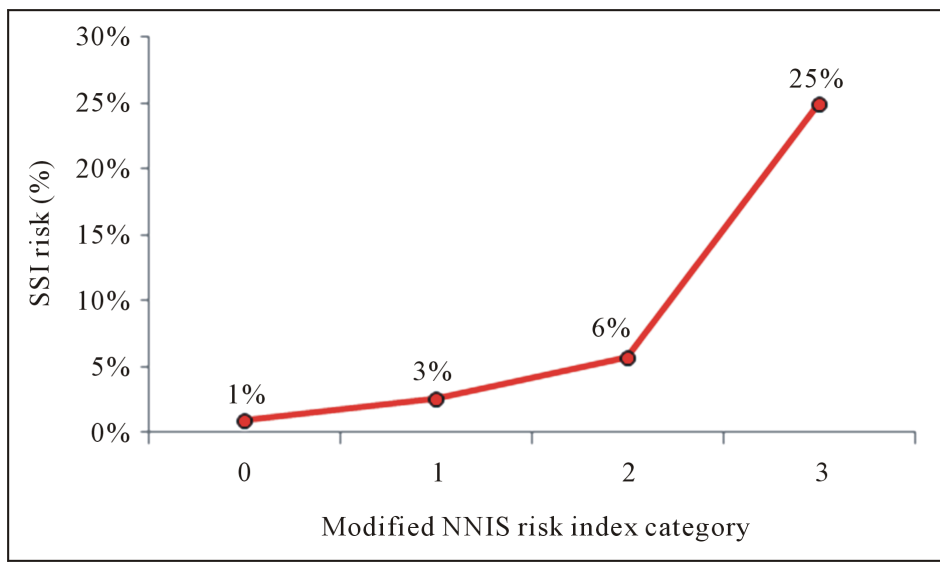

Figure 1. Risk of surgical site infection versus modified NNIS risk index.

44\%. Despite the advances in antibiotic prophylaxis, skin preparation remains as an important factor in reducing the risk of SSI [3] [4]. There are different antiseptic solutions for skin preparation for surgery, but it seems to be a consensus that there is no difference between these agents [3] [4] despite one study that shows less incidence of SSI with povidone iodine preparation [8].

The only preoperative risk factor suggested by our study was the ASA score. All the other risk factors indicated were operative factors. The ASA score is an indicator of the impact of comorbidities in the patient's general health. A score equal to or greater than 3 is associated with increased risk of infection after surgery by some authors [3] [4]. Our study corroborated with that, as an ASA score higher than 2 was indicated as a risk factor for the development of SSI. It is important, then, to reiterate the importance of careful and planned preoperative assessment of the patient in order to minimize the risk of infection.

Although none of our references studied the number of professionals at surgery, [9] indicates that traffic in the operating room can increase the load of airborne microorganisms and that the laminar flow suffers interference from the various door openings increasing the risk of SSI. In our study, a number of professionals at surgery greater than 2 was pointed as a risk factor for SSI. When analyzed as a continuous variable, it did not yield a statistically significant result. We suggest caution in the interpretation of this variable. However, keeping surgery staff and traffic in the operating room to a minimum are good measures to avoid infection.

The length of hospital stay before surgery was also indicated as risk factor for SSI after THA in our study and not explored in our references. Seriated genotyping evaluations are necessary to better determine the period after which the skin is colonized by hospital microorganisms. Duration of surgery, on the other hand, is associated with increased risk of SSI [3] [4] [10] and it had no statistical significance in our study. Reference [10] relates prolonged surgery time with more complex cases, which involve more extensile exposures and greater tissue damage leading to higher rates of infection.

Some authors [4] [11] suggest possible mechanisms of the benefits of neuraxial anesthesia instead of general anesthesia in orthopedic procedures. They include better tissue perfusion and immune function and diminishes blood loss. Our study also suggests general anesthesia as a risk factor for infection.

Antibiotic prophylaxis is a well-established method to prevent post-surgery infection [3] [4]. An increase in the risk of infection has been associated with failure to adhere to antibiotic prophylaxis protocols, be it in dosage or timing [4]. Our analysis was impaired due to missing data regarding antibiotic prophylaxis use. Even then, it strongly suggests the use of antibiotics to be a protective factor against SSI.

\section{Conclusions}

Surgical site infection is one of the most common complications after THA. Our study estimates a rate of SSI in five Brazilian general hospitals that are almost three times higher than international studies. Identifying risk factors and addressing them prior to the procedure is key in preventing SSI.

Our analysis points that an ASA score higher than 2, the use of general anesthesia, and the number of professionals at surgery higher than 2 are risk factors for the development of SSI after THA. In our multivariate analysis, only the Modified NNIS risk index is pointed as a risk factor for SSI. Antibiotic prophylaxis is suggested to 
be a protective measure against SSI.

As a retrospective analysis, this study has several limitations. Nonetheless, it suggests important opportunities to improve the quality of care and to prevent SSI in hip arthroplasty, such as avoiding general anesthesia, keeping the operative staff to a minimum and diminishing traffic in the operating room. Elaboration of new pre-surgery protocols or reviewing the current ones and adherence to them, as well as proper collection of data for future analysis may be important measures to decrease the risk of infection in the studied hospitals.

\section{Acknowledgements}

We would like to thank FAPEMIG (Fundação de Amparo à Pesquisa do Estado de Minas Gerais) for their continuing effort in supporting and stimulating scientific projects and technologic innovation in Brazil.

\section{References}

[1] Liu, X.-W., Zi, Y., Xiang, L.-B. and Wang, Y. (2015) Total Hip Arthroplasty: A Review of Advances, Advantages and Limitations. International Journal of Clinical and Experimental Medicine, 8, 27-36. http://www.ncbi.nlm.nih.gov/pmc/articles/PMC4358426/

[2] Tsertsvadze, A., Grove, A., Freeman, K., Court, R., Johnson, S., Connock, M., et al. (2014) Total Hip Replacement for the Treatment of End Stage Arthritis of the Hip: A Systematic Review and Meta-Analysis. PloS ONE, 9, e99804. http://dx.doi.org/10.1371/journal.pone.0099804

[3] Shahi, A. and Parvizi, J. (2015) Prevention of Periprosthetic Joint Infection. Archives of Bone and Joint Surgery, 3, $72-$ 81. http://www.ncbi.nlm.nih.gov/pmc/articles/PMC4468618/

[4] Triantafyllopoulos, G., Stundner, O., Memtsoudis, S. and Poultsides, L.A. (2015) Patient, Surgery, and Hospital Related Risk Factors for Surgical Site Infections Following Total Hip Arthroplasty. The Scientific World Journal, 2015, Article ID: 979560. http://dx.doi.org/10.1155/2015/979560

[5] Gillespie, B.M., Kang, E., Roberts, S., Lin, F., Morley, N., Finigan, T., et al. (2015) Reducing the Risk of Surgical Site Infection Using a Multidisciplinary Approach: An Integrative Review. Journal of Multidisciplinary Healthcare, 8, 473487. http://dx.doi.org/10.2147/JMDH.S73565

[6] Forster-Horvath, C., Egloff, C., Valderrabano, V. and Nowakowski, A.M. (2014) The Painful Primary Hip Replacement-Review of the Literature. Swiss Medical Weekly, 144, w13974. http://dx.doi.org/10.4414/smw.2014.13974

[7] von Eiff, C., Becker, K., Machka, K., Stammer, H. and Peters, G. (2001) Nasal Carriage as a Source of Staphylococcus aureus Bacteremia. Study Group. The New England Journal of Medicine, 344, 11-16. http://dx.doi.org/10.1056/NEJM200101043440102

[8] Carroll, K., Dowsey, M., Choong, P. and Peel, T. (2014) Risk Factors for Superficial Wound Complications in Hip and Knee Arthroplasty. Clinical Microbiology and Infection, 20, 130-135. http://dx.doi.org/10.1111/1469-0691.12209

[9] Andersson, A.E., Bergh, I., Karlsson, J., Eriksson, B.I. and Nilsson, K. (2012) Traffic Flow in the Operating Room: An Explorative and Descriptive Study on Air Quality during Orthopedic Trauma Implant Surgery. American Journal of Infection Control, 40, 750-755. http://dx.doi.org/10.1016/j.ajic.2011.09.015

[10] Ridgeway, S., Wilson, J., Charlet, A., Kafatos, G., Pearson, A. and Coello, R. (2005) Infection of the Surgical Site after Arthroplasty of the Hip. Journal of Bone \& Joint Surgery, 87-B, 844-850. http://dx.doi.org/10.1302/0301-620X.87B6.15121

[11] Liu, J., Ma, C., Elkassabany, N., Fleisher, L.A. and Neuman, M.D. (2013) Neuraxial Anesthesia Decreases Post-Operative Systemic Infection Risk Compared to General Anesthesia in Knee Arthroplasty. Anesthesia and Analgesia, 117, 1010-1016. http://dx.doi.org/10.1213/ANE.0b013e3182a1bf1c 


\section{List of Abbreviations}

THA-Total Hip Arthroplasty

SSI-Surgical Site Infection

NNIS-National Nosocomial Infections Surveillance

HICC-Hospital Infection Control Committee

NHSN_-National Healthcare Safety Network

ASA-American Society of Anesthesiologists

C.I.-Confidence Interval 